OPEN ACCESS

Edited by:

Jason W. Triplett,

Children's National Health System,

United States

Reviewed by:

Martha E. Bickford,

University of Louisville, United States

Jianhua Cang,

University of Virginia, United States

${ }^{*}$ Correspondence:

Keisuke Yonehara

keisuke.yonehara@dandrite.au.dk

Received: 30 March 2018

Accepted: 03 July 2018

Published: 24 July 2018

Citation:

Oliveira AF and Yonehara K (2018)

The Mouse Superior Colliculus as a Model System for Investigating Cell

Type-Based Mechanisms of Visual

Motor Transformation.

Front. Neural Circuits 12:59.

doi: 10.3389/fncir.2018.00059

\section{The Mouse Superior Colliculus as a Model System for Investigating Cell Type-Based Mechanisms of Visual Motor Transformation}

\author{
Ana F. Oliveira ${ }^{1,2}$ and Keisuke Yonehara ${ }^{1,2 *}$ \\ ' DANDRITE - Danish Research Institute of Translational Neuroscience, Nordic EMBL Partnership for Molecular Medicine, \\ Aarhus, Denmark, ${ }^{2}$ Department of Biomedicine, Aarhus University, Aarhus, Denmark
}

The mouse superior colliculus (SC) is a laminar midbrain structure involved in processing and transforming multimodal sensory stimuli into ethologically relevant behaviors such as escape, defense, and orienting movements. The SC is unique in that the sensory (visual, auditory, and somatosensory) and motor maps are overlaid. In the mouse, the SC receives inputs from more retinal ganglion cells than any other visual area. This makes the mouse SC an ideal model system for understanding how visual signals processed by retinal circuits are used to mediate visually guided behaviors. This Perspective provides an overview of the current understanding of visual motor transformations operated by the mouse SC and discusses the challenges to be overcome when investigating the input-output relationships in single collicular cell types.

Keywords: superior colliculus, visual processing, sensorimotor transformation, retinal ganglion cell, functional connectivity

\section{INTRODUCTION}

The superior colliculus (SC) is an evolutionarily conserved brain region found in mammals, homologous to the tectum in non-mammalian vertebrate species. It receives retinotopically organized synaptic inputs from retinal ganglion cells and reconstructs the spatial structure of the visual image (Cang and Feldheim, 2013; Cang et al., 2018). Historically, the SC has been studied in order to understand two different biological problems. The first is the mechanisms governing how topographic axonal projections from the chick and mouse retinas become established. These rely on axon guidance molecules (Frisén et al., 1998; Feldheim et al., 2000; Sweeney et al., 2015; Ito and Feldheim, 2018) and on spontaneous retinal waves (Chandrasekaran, 2005; Liu et al., 2014; Ito and Feldheim, 2018). However, until recently, the diversity of presynaptic retinal ganglion cell types (Kong et al., 2005; Völgyi et al., 2009; Sümbül et al., 2014; Baden et al., 2016) and postsynaptic collicular cell types (Mooney et al., 1988b; Gale and Murphy, 2014; Shang et al., 2015) has seldom been related to the organization of the retino-collicular projection (McIlwain, 1978; Hong et al., 2011; Joesch et al., 2016; Reinhard et al., 2018). The second problem concerns the neural mechanisms underlying saccadic eye movements in non-human primates (Schiller et al., 1980, 1979; Campos et al., 2006; Basso and May, 2017).

In rodents, the SC has also been used for studying innate behaviors related to avoidance or orientation (Sahibzada et al., 1986; Dean et al., 1988, 1989). These output behaviors are of great ecological value: the detection of (and consequent escape from) a predator, or effective localization 
and orientation adjustments to catch prey, can determine survival. Although these SC functions were uncovered several decades ago, it was not until recently that the physiological and behavioral roles of each collicular cell type began to be investigated (Gale and Murphy, 2014; Shang et al., 2015, 2018; Wei et al., 2015).

In the coming years, we expect we will determine a unified understanding of the function of the mouse SC at many levels: from gene function, cell types, and circuits to behavior. This Perspective aims to discuss the advantages of using the mouse SC as a model system for investigating the contribution of individual visual channels to visually guided behaviors, and proposes future research directions.

\section{FUNCTIONAL ORGANIZATION OF THE SUPERFICIAL LAYERS OF THE MOUSE SUPERIOR COLLICULUS}

The SC can be subdivided in the visuosensory and the motor layers. The latter consists of the intermediate and deeper layers. The superficial layers are visuosensory and include (from the surface): the stratum zonale (SZ), the stratum griseum superficiale (SGS), and the stratum opticum (SO; May, 2006; Ito and Feldheim, 2018).

In the mouse, the superficial layers of the SC (sSC) are the major retino-recipient structure in the brain, receiving input from ca. 90\% of retinal ganglion cells (Ellis et al., 2016), and from the striate and extrastriate visual cortex (Wang and Burkhalter, 2013).

Visual responses to the appearance, disappearance, or movement of a stimulus were first detected in the mouse sSC several decades ago (Dräger and Hubel, 1975a,b). Later, single-unit extracellular recordings from the sSC in anesthetized mice during visual stimulation revealed several types of visual responses, including ON/OFF responses to flashing spot stimuli and orientation-selective (OS) responses. Interestingly, there were no changes in OS responses following a V1 lesion or dark-rearing-mediated visual deprivation (Wang et al., 2010), suggesting that collicular OS responses might either emerge de novo in the SC or be inherited from the retina. In addition, in vivo two-photon calcium imaging recordings identified direction-selective (DS) neurons in the most superficial lamina of the SC, the density of which declines with increasing distance from the surface of the SC (Inayat et al., 2015). Recently, it has been reported that DS responses in the sSC are inherited from the retina (Shi et al., 2017).

\section{THE SC AS A MODEL SYSTEM FOR VISUAL PROCESSING}

Visual processing begins in the retina, where ca. 40 types of ganglion cells have been identified (Baden et al., 2016). Evidence from zebrafish (Robles et al., 2014) and mice (Ellis et al., 2016) indicates that there is massive divergence and convergence of axonal projections from retinal ganglion cell types to the brain. In other words, many ganglion cells project to multiple brain targets using collaterals (Ellis et al., 2016; Huang et al., 2017), and single brain centers receive inputs from multiple retinal ganglion cell types (Ellis et al., 2016; Reinhard et al., 2018). However, it is not yet understood how different ganglion cell types contribute to animal behavior, except for a few specialized cell types such as melanopsinpositive ganglion cells (Chen et al., 2011; Schmidt et al., 2011) or ON DS cells (Yonehara et al., 2009; Dhande et al., 2013).

The retina can be viewed as a parallel assemblage of small circuit modules represented by approximately 40 mosaics of retinal ganglion cells. Is the SC also functionally organized in parallel modules, operating the same computation throughout the SC? Recently, a column-like organization of OS cells was identified in the mouse SC where all angles and positions are not covered uniformly in the sSC. Feinberg and Meister (2015) revealed large patches containing OS cells with similar tuning. Ahmadlou and Heimel (2015) reported that neurons in the same column tend to prefer the same orientation, which is parallel to the concentric circle around the center of the visual field; this spatial organization could allow SC neurons to best respond to an expanding and receding optic flow. Another example of non-uniform coverage is the clustered distribution of the axon terminals of a transient OFF alpha ganglion cell type (Huberman et al., 2008) and an ON-OFF DS ganglion cell type (RivlinEtzion et al., 2011) along the surface of the SC, failing to cover all retinotopic locations on the SC. Investigating the synaptic and circuit mechanisms underlying the tuning to the expanding and receding optic flow in the sSC could reveal the key principles governing retino-collicular visual processing.

\section{THE SC MEDIATES TRACTABLE BEHAVIORS}

The rodent SC has commonly been associated with three types of output: escape/freezing defense-like behaviors, orienting movements, and autonomic responses. Defense-like behaviors consist of movements directed away from aversive stimuli, whereas orienting movements are generally directed toward attractive stimuli (Dean et al., 1989). Autonomic responses include marked changes in heart rate and blood pressure, and cortical arousal in response to visual emergencies (Redgrave and Dean, 1985; Keay et al., 1988).

Investigations into avoidance behaviors after visual stimulation have demonstrated that mice freeze and/or escape in response to a looming stimulus in the upper visual field, but not in the lower visual field, thereby suggesting that behavioral decisions are made based on the location of the stimulus within the visual field (Yilmaz and Meister, 2013; DeFranceschi et al., 2016). Follow-up studies have revealed that the sSC play a role in this behavior (Shang et al., 2015, 2018; Wei et al., 2015; Huang et al., 2017). 
Orienting movements performed by the mouse are also being investigated. Mice exposed to crickets exhibit robust prey capture behavior and this behavior relies on vision (Hoy et al., 2016). While it has not yet been confirmed that the SC has a role in prey capture behavior in the mouse, undercutting the SC in the hamster impaired the pursuit of crickets (Finlay et al., 1980). Similarly, the SC has been shown to be involved in prey capture in other vertebrates (Ewert, 1974; Semmelhack et al., 2014).

\section{THE SC AS A MODEL SYSTEM FOR SENSORIMOTOR TRANSFORMATION}

The SC processes both aversive and appetitive visual stimuli, generating motor output responses related to avoidance and orientation, but the exact contributions of different retinal ganglion cell types to these visual motor transformations are not yet understood.

It has been suggested that one type of OFF ganglion cell in the retina is approach sensitive, as it responds to expanding, but not receding, black spots (Münch et al., 2009). Another population of ganglion cells, characterized as having the smallest and densest receptive fields, is thought to serve as an alarm neuron for overhead predators (Zhang Y. et al., 2012). How these approach or alarm retinal signals are processed by the sSC circuitry and transmitted to downstream premotor areas remains unknown.

Interestingly, stimulating the medial SC evokes avoidance or defense reactions in rodents, whereas stimulating the lateral SC elicits orienting or approach responses (Sahibzada et al., 1986; Dean et al., 1988). Because the medial and lateral SCs analyze the upper and lower visual field, respectively, these findings echo the behavioral observations that looming stimuli evoke escape/freeze behaviors only when presented from above.

Neurons in the sSC project to the intermediate (iSC) and deep layers (dSC) of the SC (Mooney et al., 1988a). Projections from deeper layers to the nuclei of the brainstem can be either contralateral (from the lateral regions of the SC) or ipsilateral (from medial regions; Bickford and Hall, 1989). Consequently, contralateral projections tend to mediate orienting behaviors, while ipsilateral projections tend to mediate avoidance behaviors (Redgrave et al., 1996a,b; Comoli et al., 2012). In line with these findings, stimulating the cuneiform nucleus $(\mathrm{Cn})$ and the parabigeminal nucleus $(\mathrm{PbG})$, two of the main targets of ipsilateral descending projections (Redgrave et al., 1987), evokes escape/freezing behaviors in rodents (Parker and Sinnamon, 1983; Mitchell et al., 1988; Shang et al., 2015; Caggiano et al., 2018). Furthermore, the $\mathrm{Cn}$ receives projections from the medial part of the SC, a region representing the upper visual field (Westby et al., 1990). Future research should examine how distinct dSC output cells collect information from retinal ganglion cell types via sSC neurons to extract salient features from the visual scene (Figure 1).
Together, these reports suggest that visual pathways dedicated to survival-related behaviors are hard-wired by segregated neuronal projections, possibly by intrinsic genetic mechanisms.

\section{GENETIC LABELING OF SC CELL TYPES IN MICE}

To understand the circuit mechanisms underlying visual processing and sensorimotor transformation, cell type-based studies are crucial, as they make it possible to link light responses, connectivity, behavior, and gene expression (Figure 1). As with zebrafish (Robles et al., 2011), gaining genetic access to cell types in the mouse SC will be critical for untangling the functional connectivity of neuronal circuits in the SC.

To date, four distinct cell types have been identified in the mouse sSC: narrow-field, wide-field, horizontal, and stellate cells. It has been suggested that a group of small cells at the border of the SZ, with dendrites extending toward the upper SGS, make up a fifth cell type, the marginal cells (May, 2006). However, attempts to characterize the electrophysiological properties of this cell type have failed to distinguish it from stellate cells (Gale and Murphy, 2014). Nonetheless, a population of DS cells with compact receptive fields, containing both excitatory and inhibitory neurons, has been found in the superficial SGS: these could be marginal cells (Inayat et al., 2015).

Narrow-field cells are labeled with Cre recombinase in the transgenic mouse Grp-KH288-Cre (Gerfen et al., 2013; Gale and Murphy, 2014). They are small, with thick dendrites extending dorsally toward the SC surface and ventrally toward the SC deeper layers. They have small receptive fields, respond to slowly moving stimuli and are DS (Gale and Murphy, 2014). Narrow-field cells project to the deeper layers of the $\mathrm{SC}$ and to the $\mathrm{PbG}$ (Figure 1). Given their projection pattern and their physiological responses, it is tempting to speculate that these cells could be involved in signaling the location of salient visual inputs to the iSC and therefore shifting the gaze toward a target, and/or in avoidance responses mediated by the SC-PbG-amygdala pathway (Shang et al., 2015).

Wide-field cells are labeled with Cre recombinase in the transgenic mouse Ntsr1-GN209-Cre (Gerfen et al., 2013; Gale and Murphy, 2014). These cells display dendrites extending diagonally to the surface of the SC and forming a large field. They respond best to slowly moving stimuli and can be DS and/or OS. These cells project to the lateral posterior nucleus of the thalamus (LP; Figure 1; Gale and Murphy, 2014), which makes them a good candidate to mediate avoidance behaviors via the pathway connecting the SC-LP-amygdala (Wei et al., 2015).

Horizontal cells are labeled with Cre recombinase in the transgenic mouse line GAD2-Cre (Gerfen et al., 2013; Gale and Murphy, 2014). These cells have large receptive fields, respond best to either large stationary or fast-moving visual stimuli, and are rarely DS. They provide inhibitory input to both the dorsal and ventral lateral geniculate nucleus of the thalamus (LGN) and to the PbG (Figure 1; Gale and Murphy, 2014). 

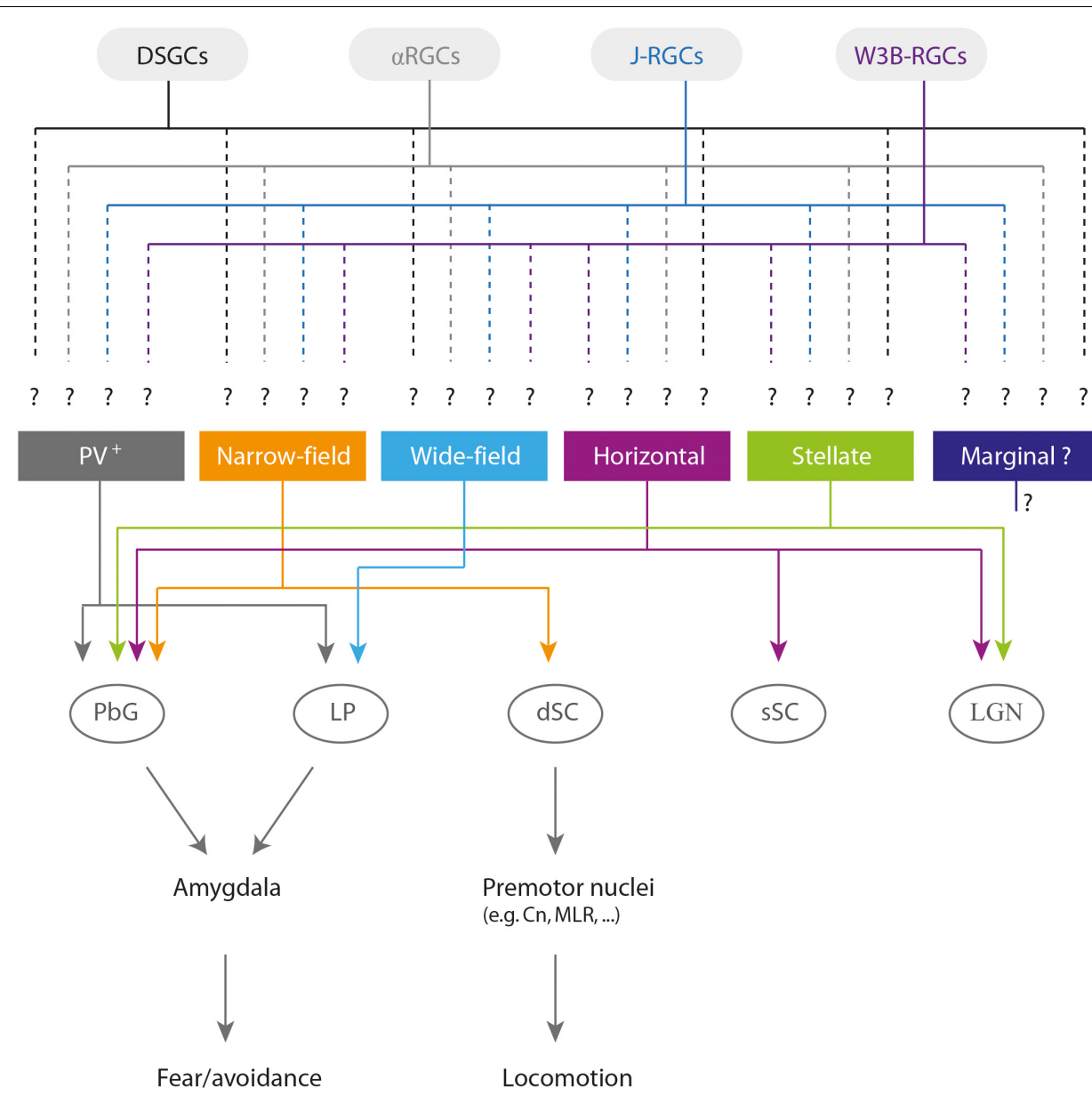

FIGURE 1 | Overview of the sSC cell types (Gale and Murphy, 2014; Inayat et al., 2015; Shang et al., 2015, 2018), potential inputs from retinal ganglion cell types (Sanes and Masland, 2015), relevant output brain targets, and behavioral roles. Note that the identity of the retinal ganglion cells projecting to each collicular cell type remains unknown. Abbreviations: DSGCs, direction-selective ganglion cells; $\alpha$ RGCs, alpha retinal ganglion cells; J-RGCs, JAM-B-expressing OFF retinal ganglion cells; PV+, parvalbumin-positive neurons; dSC, deep layers of the superior colliculus; PbG, parabigeminal nucleus; LP, lateral posterior nucleus of the thalamus; sSC, superficial layers of the superior colliculus; LGN, lateral geniculate nucleus of the thalamus; Cn, cuneiform nucleus; MLR, mesencephalic locomotor region.

Stellate cells have multiple dendrites with no clear orientation and have small receptive fields. They respond best to small visual stimuli and project to both the PbG and LGN (Figure 1; Gale and Murphy, 2014, 2018). These cells are labelled in the transgenic mouse line Rorb-Cre, but horizontal and narrow-field cells are also labelled in this mouse line (Gale and Murphy, 2018), thereby hindering the investigation of the specific role of stellate cells in innate visual motor behavior.

The transgenic mouse line PV-ires-Cre labels cells in the SGS and SO known to project to the amygdala via the $\mathrm{PbG}$ and to mediate escape and freezing behavior (Figure 1; Shang et al., 2015, 2018). Recently, it has been shown that a subpopulation of parvalbumin-positive $\left(\mathrm{PV}^{+}\right)$cells located in the SO projects to the LP and specifically mediates freezing behavior (Figure 1; Shang et al., 2018). Even though it was demonstrated that the $\mathrm{PV}^{+}$neurons in these studies were glutamatergic (Shang et al., 2015, 2018), $\mathrm{PV}^{+}$cells in the SC form a distinct mixed population of glutamatergic and
GABAergic neurons with heterogeneous morphological and electrophysiological properties (Villalobos et al., 2018). While the morphological analysis described by Shang et al. (2015) suggests that these neurons might be narrow-field cells, a new report demonstrated that $\mathrm{PV}^{+}$neurons in the sSC also include stellate and horizontal cells (Villalobos et al., 2018). The diversity encountered among $\mathrm{PV}^{+}$neurons could indicate that these neurons serve multiple circuit and behavioral functions.

\section{FUTURE DIRECTIONS AND CHALLENGES: VISUAL MOTOR TRANSFORMATION AT THE LEVEL OF A SINGLE CELL TYPE}

A plethora of new molecular, genetic, and imaging tools that has become available in recent years now means that visual motor 
transformations can be dissected at the single-cell type level. These tools make it possible to identify the locus of synapses within specific neuronal circuits mediating visual motor integration; this information will enable molecular and activitydependent mechanisms underlying the circuit assembly to be studied.

Advances in mouse genetics have provided most of the essential tools for exploring the role of single cell types in visual motor behavior. Multiple mouse lines are now available, expressing Cre recombinase in specific cell types of particular brain regions (Taniguchi et al., 2011; Gerfen et al., 2013). However, a systematic approach for identifying and labeling SC cell types has rarely been applied (Byun et al., 2016). An unbiased method for characterizing cell types based on gene expression pattern, such as dropSeq (Klein et al., 2015; Macosko et al., 2015), could be used to identify cell types based on specific molecular markers. These could, then, be exploited to create transgenic mice in which a single cell type is labeled with Cre recombinase. Other approaches for targeting individual cell types could be selecting AAVs with tropism and/or a promoter for selective neuronal populations (Dimidschstein et al., 2016), or nanobodies that are reconstituted only when presented with a specific antigen (Tang et al., 2013).

Having a valuable collection of mouse lines with labeled SC cell types will provide excellent opportunities for linking their activity and connectivity. It will then be possible to examine how the convergence of ganglion cell types is organized at the level of brain targets' single cell types (Figure 1; Rompani et al., 2017) by combining trans-synaptic tracing with modified viral tracers expressing activity sensors and two-photon imaging (Yonehara et al., 2013; Wertz et al., 2015; Zingg et al., 2017).

Another unanswered question is how retinal signals processed by the sSC circuitry are transmitted to downstream premotor areas (Figure 1). Recent work has examined a similar problem using retrograde rabies virus-based trans-synaptic circuit tracing, and determined the combinations of neuronal pathways originating from retinal ganglion cell types projecting to two brain centers that mediate avoidance responses via the sSC (Reinhard et al., 2018). Follow-up experiments using specific inactivation and activation of the involved retinal ganglion cell types will be fundamental to understanding the contribution of each ganglion cell type to visual motor transformations.

Next, it will be imperative to examine how the retinocollicular connectivity that underlies visual processing operated by individual genetically labeled SC cell types is established by genetic- and activity-dependent mechanisms. The genetic mechanisms can be analyzed by testing the effect of gene knockdown in genetically labelled presynaptic ganglion cell types or postsynaptic sSC cell types, using conditional knockout mice or adeno-associated virus- or electroporation-mediated cell type-specific delivery of RNAi or CRISPR/Cas9 constructs. The contribution of activitydependent mechanisms can be addressed by transiently activating or suppressing presynaptic or postsynaptic activity in a cell type- and developmental-specific manner, using optogenetic and chemogenetic tools (Zhang J. et al., 2012).

Finally, understanding to what extent the mechanistic insights obtained from the mouse SC are conserved across different animal species will be fundamental. Such work will deepen our understanding of how the species-specific functional organization of the SC is built to meet ethological requirements.

\section{CONCLUSION}

Here, we propose the mouse SC as an outstanding model for investigating sensorimotor transformation at the single-cell level. First, the laminar organization of the mouse (May, 2006) facilitates the identification of individual cell types. Second, the mouse is a genetically tractable animal and individual cell types can be labelled with DNA recombinase (Gerfen et al., 2013; Gale and Murphy, 2014), enabling manipulation and monitoring of specific collicular cell types. Third, the sSC receives monosynaptic inputs from retinal ganglion cells (Ellis et al., 2016) and is located relatively superficially, being accessible for imaging with two-photon microscopy (Ahmadlou and Heimel, 2015; Feinberg and Meister, 2015). Fourth, in the mouse, ca. $90 \%$ of the retinal ganglion cells project to the SC. Fifth, several behavioral paradigms are available for probing visual motor transformations processed by the SC (Shang et al., 2015; Wei et al., 2015). Last, breeding mice is faster, cheaper, and easier than breeding non-human primates, making the mouse a readily available tool to the wider scientific community. For these reasons, we expect the mouse SC to become heavily studied in the next years as a valuable system for examining cell type-based mechanisms underlying visual motor processing.

\section{AUTHOR CONTRIBUTIONS}

$\mathrm{AO}$ and $\mathrm{KY}$ wrote, edited, and revised the manuscript.

\section{FUNDING}

KY acknowledges grants from Lundbeckfonden, European Research Council Starting Grant (638730) and Novo Nordisk Foundation. AO was funded by a Marie Skłodowska-Curie individual fellowship "RETICULUS" and a MOBILEX grant from the Danish Research Council.

\section{ACKNOWLEDGMENTS}

We thank DANDRITE co-financed by Lundbeckfonden and Aarhus University. We also thank Sara Oakeley for commenting on the manuscript. 


\section{REFERENCES}

Ahmadlou, M., and Heimel, J. A. (2015). Preference for concentric orientations in the mouse superior colliculus. Nat. Commun. 6:6773. doi: 10.1038/ ncomms 7773

Baden, T., Berens, P., Franke, K., Bethge, M., and Euler, T. (2016). The functional diversity of retinal ganglion cells in the mouse. Nature 529, 345-350. doi: $10.1038 /$ nature 16468

Basso, M. A., and May, P. J. (2017). Circuits for action and cognition: a view from the superior colliculus. Annu. Rev. Vis. Sci. 3, 197-226. doi: 10.1146/annurevvision-102016-061234

Bickford, M. E., and Hall, W. C. (1989). Collateral projections of predorsal bundle cells of the superior colliculus in the rat. J. Comp. Neurol. 283, 86-106. doi: $10.1002 /$ cne. 902830108

Byun, H., Kwon, S., Ahn, H. J., Liu, H., Forrest, D., Demb, J. B., et al. (2016). Molecular features distinguish ten neuronal types in the mouse superficial superior colliculus. J. Comp. Neurol. 524, 2300-2321. doi: 10.1002/cne. 23952

Caggiano, V., Leiras, R., Goñi-Erro, H., Masini, D., Bellardita, C., Bouvier, J., et al. (2018). Midbrain circuits that set locomotor speed and gait selection. Nature 553, 455-460. doi: 10.1038/nature25448

Campos, M., Cherian, A., and Segraves, M. A. (2006). Effects of eye position upon activity of neurons in macaque superior colliculus. J. Neurophysiol. 95, 505-526. doi: $10.1152 /$ jn.00639.2005

Cang, J., and Feldheim, D. A. (2013). Developmental mechanisms of topographic map formation and alignment. Annu. Rev. Neurosci. 36, 51-77. doi: 10.1146/ annurev-neuro-062012-170341

Cang, J., Savier, E., Barchini, J., and Liu, X. (2018). Visual function, organization, and development of the mouse superior colliculus. Annu. Rev. Vis. Sci. doi: 10.1146/annurev-vision-091517-034142 [Epub ahead of print].

Chandrasekaran, A. R. (2005). Evidence for an instructive role of retinal activity in retinotopic map refinement in the superior colliculus of the mouse. J. Neurosci. 25, 6929-6938. doi: 10.1523/JNEUROSCI.1470-05.2005

Chen, S. K., Badea, T. C., and Hattar, S. (2011). Photoentrainment and pupillary light reflex are mediated by distinct populations of ipRGCs. Nature 476, 92-96. doi: 10.1038/nature10206

Comoli, E., Das Neves Favaro, P., Vautrelle, N., Leriche, M., Overton, P. G., and Redgrave, P. (2012). Segregated anatomical input to sub-regions of the rodent superior colliculus associated with approach and defense. Front. Neuroanat. 6:9. doi: $10.3389 /$ fnana.2012.00009

Dean, P., Mitchell, I. J., and Redgrave, P. (1988). Responses resembling defensive behaviour produced by microinjection of glutamate into superior colliculus of rats. Neuroscience 24, 501-510. doi: 10.1016/0306-4522(88) 90345-4

Dean, P., Redgrave, P., and Westby, G. W. (1989). Event or emergency? Two response systems in the mammalian superior colliculus. Trends Neurosci. 12, 137-147. doi: 10.1016/0166-2236(89)90052-0

DeFranceschi, G., Vivattanasarn, T., Saleem, A., and Solomon, S. (2016). Vision guides selection of freeze or flight defense strategies in mice. Curr. Biol. 26, 2150-2154. doi: 10.1016/j.cub.2016.06.006

Dhande, O. S., Estevez, M. E., Quattrochi, L. E., El-Danaf, R. N., Nguyen, P. L., Berson, D. M., et al. (2013). Genetic dissection of retinal inputs to brainstem nuclei controlling image stabilization. J. Neurosci. 33, 17797-17813. doi: 10. 1523/JNEUROSCI.2778-13.2013

Dimidschstein, J., Chen, Q., Tremblay, R., Rogers, S. L., Saldi, G.-A., Guo, L., et al. (2016). A viral strategy for targeting and manipulating interneurons across vertebrate species. Nat. Neurosci. 19, 1743-1749. doi: 10.1038/nn.4430

Dräger, U. C., and Hubel, D. H. (1975a). Physiology of visual cells in mouse superior colliculus and correlation with somatosensory and auditory input. Nature 253, 203-204. doi: 10.1038/253203a0

Dräger, U. C., and Hubel, D. H. (1975b). Responses to visual stimulation and relationship between visual, auditory, and somatosensory inputs in mouse superior colliculus. J. Neurophysiol. 38, 690-713.

Ellis, E. M., Gauvain, G., Sivyer, B., and Murphy, G. J. (2016). Shared and distinct retinal input to the mouse superior colliculus and dorsal lateral geniculate nucleus. J. Neurophysiol. 116, 602-610. doi: 10.1152/jn.00227.2016
Ewert, J. P. (1974). The neural basis of visually guided behavior. Sci. Am. 230, 34-42. doi: 10.1038/scientificamerican0374-34

Feinberg, E. H., and Meister, M. (2015). Orientation columns in the mouse superior colliculus. Nature 519, 232-299. doi: 10.1038/nature14103

Feldheim, D. A., Kim, Y.-I., Bergemann, A. D., Frisén, J., Barbacid, M., and Flanagan, J. G. (2000). Genetic analysis of Ephrin-A2 and Ephrin-A5 shows their requirement in multiple aspects of retinocollicular mapping. Neuron 25, 563-574. doi: 10.1016/S0896-6273(00)81060-0

Finlay, B. L., Sengelaub, D. R., Berg, A. T., and Cairns, S. J. (1980). A neuroethological approach to hamster vision. Behav. Brain Res. 1, 479-496. doi: 10.1016/0166-4328(80)90003-0

Frisén, J., Yates, P. A., McLaughlin, T., Friedman, G. C., O’Leary, D. D. M., and Barbacid, M. (1998). Ephrin-A5 (AL-1/RAGS) is essential for proper retinal axon guidance and topographic mapping in the mammalian visual system. Neuron 20, 235-243. doi: 10.1016/S0896-6273(00)80452-3

Gale, S. D., and Murphy, G. J. (2014). Distinct representation and distribution of visual information by specific cell types in mouse superficial superior colliculus. J. Neurosci. 34, 13458-13471. doi: 10.1523/JNEUROSCI.276814.2014

Gale, S. D., and Murphy, G. J. (2018). Distinct cell types in the superficial superior colliculus project to the dorsal lateral geniculate and lateral posterior thalamic nuclei. J. Neurophysiol. doi: 10.1152/jn.00248.2018 [Epub ahead of print].

Gerfen, C. R., Paletzki, R., and Heintz, N. (2013). GENSAT BAC cre-recombinase driver lines to study the functional organization of cerebral cortical and basal ganglia circuits. Neuron 80, 1368-1383. doi: 10.1016/j.neuron.2013. 10.016

Hong, Y. K., Kim, I. J., and Sanes, J. R. (2011). Stereotyped axonal arbors of retinal ganglion cell subsets in the mouse superior colliculus. J. Comp. Neurol. 519, 1691-1711. doi: 10.1002/cne.22595

Hoy, J. L., Yavorska, I., Wehr, M., and Niell, C. M. (2016). Vision drives accurate approach behavior during prey capture in laboratory mice. Curr. Biol. 26, 3046-3052. doi: 10.1016/j.cub.2016.09.009

Huang, L., Yuan, T., Tan, M., Xi, Y., Hu, Y., Tao, Q., et al. (2017). A retinoraphe projection regulates serotonergic activity and loomingevoked defensive behaviour. Nat. Commun. 8:14908. doi: 10.1038/ncomms 14908

Huberman, A. D., Manu, M., Koch, S. M., Susman, M. W., Lutz, A. B., Ullian, E. M., et al. (2008). Architecture and activity-mediated refinement of axonal projections from a mosaic of genetically identified retinal ganglion cells. Neuron 59, 425-438. doi: 10.1016/j.neuron.2008.07.018

Inayat, S., Barchini, J., Chen, H., Feng, L., Liu, X., and Cang, J. (2015). Neurons in the most superficial lamina of the mouse superior colliculus are highly selective for stimulus direction. J. Neurosci. 35, 7992-8003. doi: 10.1523/JNEUROSCI. 0173-15.2015

Ito, S., and Feldheim, D. A. (2018). The mouse superior colliculus: an emerging model for studying circuit formation and function. Front. Neural Circuits 12:10. doi: 10.3389/fncir.2018.00010

Joesch, M., Mankus, D., Yamagata, M., Shahbazi, A., Schalek, R., SuissaPeleg, A., et al. (2016). Reconstruction of genetically identified neurons imaged by serial-section electron microscopy. eLife 5:e15015. doi: 10.7554/eLife. 15015

Keay, K. A., Redgrave, P., and Dean, P. (1988). Cardiovascular and respiratory changes elicited by stimulation of rat superior colliculus. Brain Res. Bull. 20, 13-26. doi: 10.1016/0361-9230(88)90004-4

Klein, A. M., Mazutis, L., Akartuna, I., Tallapragada, N., Veres, A., Li, V., et al. (2015). Droplet barcoding for single-cell transcriptomics applied to embryonic stem cells. Cell 161, 1187-1201. doi: 10.1016/j.cell.2015. 04.044

Kong, J. H., Fish, D. R., Rockhill, R. L., and Masland, R. H. (2005). Diversity of ganglion cells in the mouse retina: unsupervised morphological classification and its limits. J. Comp. Neurol. 489, 293-310. doi: 10.1002/cne. 20631

Liu, M., Wang, L., and Cang, J. (2014). Different roles of axon guidance cues and patterned spontaneous activity in establishing receptive fields in the mouse superior colliculus. Front. Neural Circuits 8:23. doi: 10.3389/fncir.2014. 00023 
Macosko, E. Z., Basu, A., Satija, R., Nemesh, J., Shekhar, K., Goldman, M., et al. (2015). Highly parallel genome-wide expression profiling of individual cells using nanoliter droplets. Cell 161, 1202-1214. doi: 10.1016/j.cell.2015. 05.002

May, P. J. (2006). The mammalian superior colliculus: laminar structure and connections. Prog. Brain Res. 151, 321-378. doi: 10.1016/S0079-6123(05) 51011-2

McIlwain, J. T. (1978). Cat superior colliculus: extracellular potentials related to W-cell synaptic actions. J. Neurophysiol. 41, 1343-1358. doi: 10.1152/jn.1978. 41.5.1343

Mitchell, I. J., Dean, P., and Redgrave, P. (1988). The projection from superior colliculus to cuneiform area in the rat. II. Defence-like responses to stimulation with glutamate in cuneiform nucleus and surrounding structures. Exp. Brain Res. 72, 626-639. doi: 10.1007/BF00 250607

Mooney, R. D., Nikoletseas, M., Hess, P. R., Allen, Z., Lewin, A. C., and Rhoades, R. W. (1988a). The projection from the superficial to the deep layers of the superior colliculus: an intracellular horseradish peroxidase injection study in the hamster. J. Neurosci. 8, 1384-1399.

Mooney, R. D., Nikoletseas, M., Ruiz, S., and Rhoades, R. (1988b). Receptive-field properties and morphological characteristics of the superior collicular neurons that project to the lateral posterior and dorsal lateral geniculate nuclei in the hamster. J. Neurophysiol. 59, 1333-1351.

Münch, T. A., Da Silveira, R. A., Siegert, S., Viney, T. J., Awatramani, G. B., and Roska, B. (2009). Approach sensitivity in the retina processed by a multifunctional neural circuit. Nat. Neurosci. 12, 1308-1316. doi: 10.1038/nn. 2389

Parker, S., and Sinnamon, H. (1983). Forward locomotion elicited by electrical stimulation in the diencephalon and mesencephalon of the awake rat. Physiol. Behav. 31, 581-587.

Redgrave, P., and Dean, P. (1985). Tonic desynchronization of cortical electroencephalogram by electrical and chemical-stimulation of superior colliculus and surrounding structures in urethane-anaesthetized rats. Neuroscience 16, 659-671. doi: 10.1016/0306-4522(85)90199-X

Redgrave, P., McHaffie, J. G., and Stein, B. E. (1996a). Nociceptive neurones in rat superior colliculus. I. Antidromic activation from the contralateral predorsal bundle. Exp. Brain Res. 109, 185-196.

Redgrave, P., Simkins, M., McHaffie, J. G., and Stein, B. E. (1996b). Nociceptive neurones in rat superior colliculus. II. Effects of lesions to the contralateral descending output pathway on nocifensive behaviours. Exp. Brain Res. 109, 197-208. doi: 10.1007/BF00231781

Redgrave, P., Mitchell, I. J., and Dean, P. (1987). Descending projections from the superior colliculus in rat: a study using orthograde transport of wheatgermagglutinin conjugated horseradish peroxidase. Exp. Brain Res. 68, 147-167. doi: 10.1007/BF00255241

Reinhard, K., Li, C., Do, Q., Burke, E., Heynderickx, S., and Farrow, K. (2018). Target specific routing of visual information by the superior colliculus. bioRxiv [Preprint]. doi: 10.1101/272914

Rivlin-Etzion, M., Zhou, K., Wei, W., Elstrott, J., Nguyen, P. L., Barres, B. A., et al. (2011). Transgenic mice reveal unexpected diversity of on-off directionselective retinal ganglion cell subtypes and brain structures involved in motion processing. J. Neurosci. 31, 8760-8769. doi: 10.1523/JNEUROSCI.056411.2011

Robles, E., Laurell, E., and Baier, H. (2014). The retinal projectome reveals brain-area-specific visual representations generated by ganglion cell diversity. Curr. Biol. 24, 2085-2096. doi: 10.1016/j.cub.2014. 07.080

Robles, E., Smith, S. J., and Baier, H. (2011). Characterization of genetically targeted neuron types in the zebrafish optic tectum. Front. Neural Circuits 5:1. doi: 10.3389/fncir.2011.00001

Rompani, S. B., Müllner, F. E., Wanner, A., Zhang, C., Roth, C. N., Yonehara, K., et al. (2017). Different modes of visual integration in the lateral geniculate nucleus revealed by single-cell-initiated transsynaptic tracing. Neuron 93, 767-776. doi: 10.1016/j.neuron.2017.01.028

Sahibzada, N., Dean, P., and Redgrave, P. (1986). Movements resembling orientation or avoidance elicited by electrical stimulation of the superior colliculus in rats. J. Neurosci. 6, 723-733. doi: 10.1523/JNEUROSCI.06-0300723.1986
Sanes, J. R., and Masland, R. H. (2015). The types of retinal ganglion cells: current status and implications for neuronal classification. Annu. Rev. Neurosci. 38, 221-246. doi: 10.1146/annurev-neuro-071714-034120

Schiller, P. H., True, S. D., and Conway, J. L. (1979). Effects of frontal eye field and superior colliculus ablations on eye movements. Science 206, 590-592. doi: 10.1126/science.115091

Schiller, P. H., True, S. D., and Conway, J. L. (1980). Deficits in eye movements following frontal eye-field and superior colliculus ablations. J. Neurophysiol. 44, 1175-1189. doi: 10.1152/jn.1980.44.6.1175

Schmidt, T. M., Chen, S. K., and Hattar, S. (2011). Intrinsically photosensitive retinal ganglion cells: many subtypes, diverse functions. Trends Neurosci. 34, 572-580. doi: 10.1016/j.tins.2011.07.001

Semmelhack, J. L., Donovan, J. C., Thiele, T. R., Kuehn, E., Laurell, E., and Baier, H. (2014). A dedicated visual pathway for prey detection in larval zebrafish. eLife 9:e04878. doi: 10.7554/eLife.04878

Shang, C., Chen, Z., Liu, A., Li, Y., Zhang, J., Qu, B., et al. (2018). Divergent midbrain circuits orchestrate escape and freezing responses to looming stimuli in mice. Nat. Commun. 9:1232. doi: 10.1038/s41467-018-03580-7

Shang, C., Liu, Z., Chen, Z., Shi, Y., Wang, Q., Liu, S., et al. (2015). A parvalbuminpositive excitatory visual pathway to trigger fear responses in mice. Science 348, 1472-1477. doi: 10.1126/science.aaa8694

Shi, X., Barchini, J., Ledesma, H. A., Koren, D., Jin, Y., Liu, X., et al. (2017). Retinal origin of direction selectivity in the superior colliculus. Nat. Neurosci. 20, 550-558. doi: 10.1038/nn.4498

Sümbül, U., Song, S., McCulloch, K., Becker, M., Lin, B., Sanes, J. R., et al. (2014). A genetic and computational approach to structurally classify neuronal types. Nat. Commun. 5:3512. doi: 10.1038/ncomms4512

Sweeney, N. T., James, K. N., Sales, E. C., and Feldheim, D. A. (2015). Ephrin-As are required for the topographic mapping but not laminar choice of physiologically distinct RGC types. Dev. Neurobiol. 75, 584-593. doi: 10.1002/dneu. 22265

Tang, J. C. Y., Szikra, T., Kozorovitskiy, Y., Teixiera, M., Sabatini, B. L., Roska, B., et al. (2013). A nanobody-based system using fluorescent proteins as scaffolds for cell-specific gene manipulation. Cell 154, 928-939. doi: 10.1016/j.cell.2013. 07.021

Taniguchi, H., He, M., Wu, P., Kim, S., Paik, R., Sugino, K., et al. (2011). A resource of Cre driver lines for genetic targeting of GABAergic neurons in cerebral cortex. Neuron 71, 995-1013. doi: 10.1016/j.neuron.2011.07.026

Villalobos, C. A., Wu, Q., Lee, P. H., May, P. J., and Basso, M. A. (2018). Parvalbumin and GABA microcircuits in the mouse superior colliculus. Front. Neural Circuits 12:35. doi: 10.3389/fncir.2018.00035

Völgyi, B., Chheda, S., and Bloomfield, S. A. (2009). Tracer coupling patterns of the ganglion cell subtypes in the mouse retina. J. Comp. Neurol. 512, 664-687. doi: $10.1002 /$ cne.21912

Wang, L., Sarnaik, R., Rangarajan, K., Liu, X., and Cang, J. (2010). Visual receptive field properties of neurons in the superficial superior colliculus of the mouse. J. Neurosci. 30, 16573-16584. doi: 10.1523/JNEUROSCI.330510.2010

Wang, Q., and Burkhalter, A. (2013). Stream-related preferences of inputs to the superior colliculus from areas of dorsal and ventral streams of mouse visual cortex. J. Neurosci. 33, 1696-1705. doi: 10.1523/JNEUROSCI.306712.2013

Wei, P., Liu, N., Zhang, Z., Liu, X., Tang, Y., He, X., et al. (2015). Processing of visually evoked innate fear by a non-canonical thalamic pathway. Nat. Commun. 6:6756. doi: 10.1038/ncomms7756

Wertz, A., Trenholm, S., Yonehara, K., Hillier, D., Raics, Z., Leinweber, M., et al. (2015). Single-cell-initiated monosynaptic tracing reveals layerspecific cortical network modules. Science 349, 70-74. doi: 10.1126/science. aab1687

Westby, G. W., Keay, K. A., Redgrave, P., Dean, P., and Bannister, M. (1990). Output pathways from the rat superior colliculus mediating approach and avoidance have different sensory properties. Exp. Brain Res. 81, 626-638. doi: $10.1007 / \mathrm{BF} 02423513$

Yilmaz, M., and Meister, M. (2013). Rapid innate defensive responses of mice to looming visual stimuli. Curr. Biol. 23, 2011-2015. doi: 10.1016/j.cub.2013.08. 015

Yonehara, K., Farrow, K., Ghanem, A., Hillier, D., Balint, K., Teixeira, M., et al. (2013). The first stage of cardinal direction selectivity is localized to the 
dendrites of retinal ganglion cells. Neuron 79, 1078-1085. doi: 10.1016/j.neuron. 2013.08.005

Yonehara, K., Ishikane, H., Sakuta, H., Shintani, T., Nakamura-Yonehara, K., Kamiji, N. L., et al. (2009). Identification of retinal ganglion cells and their projections involved in central transmission of information about upward and downward image motion. PLoS One 4:e4320. doi: 10.1371/journal.pone. 0004320

Zhang, Y., Kim, I.-J., Sanes, J. R., and Meister, M. (2012). The most numerous ganglion cell type of the mouse retina is a selective feature detector. Proc. Natl. Acad. Sci. U.S.A. 109, E2391-E2398. doi: 10.1073/pnas.1211 547109

Zhang, J., Ackman, J. B., Xu, H. P., and Crair, M. C. (2012). Visual map development depends on the temporal pattern of binocular activity in mice. Nat. Neurosci. 15, 298-307. doi: 10.1038/nn. 3007
Zingg, B., Chou, X. L., Zhang, Z. G., Mesik, L., Liang, F., Tao, H. W., et al. (2017). AAV-mediated anterograde transsynaptic tagging: mapping corticocollicular input-defined neural pathways for defense behaviors. Neuron 93, 33-47. doi: 10.1016/j.neuron.2016.11.045

Conflict of Interest Statement: The authors declare that the research was conducted in the absence of any commercial or financial relationships that could be construed as a potential conflict of interest.

Copyright (C) 2018 Oliveira and Yonehara. This is an open-access article distributed under the terms of the Creative Commons Attribution License (CC BY). The use, distribution or reproduction in other forums is permitted, provided the original author(s) and the copyright owner(s) are credited and that the original publication in this journal is cited, in accordance with accepted academic practice. No use, distribution or reproduction is permitted which does not comply with these terms. 